\title{
Analysis of Activities of Adults with Aphasia at Community-Based Rehabilitation Training
}

\author{
Kiyoshi Nosu ${ }^{*}$, Ayuko Shigeta ${ }^{2}$ \\ ${ }^{1}$ Tokai University, 4-1-1 Kitakaname, Hiratsuka-shi, Kanagawa 259-1292, Japan \\ ${ }^{2}$ Shizuoka Prefectural Shimada Technical High School, 216 Achigaya, Shimada-shi, Shuzuoka 437-8541, Japan \\ Email: *nosu@wing.ncc.u-toki.ac.jp, ayu.sakura29@gmail.com
}

Received 21 August 2015; accepted 11 December 2015; published 18 December 2015

Copyright (C) 2015 by authors and Scientific Research Publishing Inc.

This work is licensed under the Creative Commons Attribution International License (CC BY). http://creativecommons.org/licenses/by/4.0/

cc) (i) Open Access

\begin{abstract}
Aphasia is a higher brain dysfunction that affects the production or comprehension of speech and the ability to read or write. The purpose of this research is to establish support guidelines based on a questionnaire survey and a language activity analysis of rehabilitation training so that volunteers can more easily assist disabled persons with aphasia. The focus of this study was the non-profit community-based intervention group Yokohama Aphasia Partner Group, which consists of members with aphasia, their families, speech-language-and-hearing therapists, psychiatric social workers, and volunteers. The following results were obtained. (1) Members with aphasia participate in the Partner Group because they can meet others with aphasia on a regular basis as well as participate in the aphasia rehabilitation program with the recovery of language functions. In addition to medical treatment, the community-based support, which improves the environment and other life contextual factors, is important for rehabilitation. (2) An individual with aphasia shows different language actions, and so an individually different support system in accordance with language activity is necessary.
\end{abstract}

\section{Keywords}

Aphasia, Rehabilitation, Community-Based-Support/Care, Language Activity

\section{Introduction}

Aphasia is a higher brain dysfunction. The National Association of Aphasia defines aphasia as follows: "Apha*Corresponding author. 
sia is an impairment of language affecting the production or comprehension of speech and the ability to read or write. Aphasia is always due to injury to the brain-most commonly from a stroke, particularly in older individuals." [1]

In addition to medical treatment, speech-language pathologists usually encourage the creation of communication-friendly environments to enable everyday participation of their aphasic clients. The results of surveys report the difficult environments of people with aphasia. For example, Howe et al. conducted interviews to investigate the environmental factors that hinder or support the community participation of adults with aphasia [2]. They identified a wide range of barriers and facilitators and several practices. Aftonomos et al. reported that community-based aphasia treatment programs routinely produce results comparable or superior to those in previously reported research [3]. These previous reports, however, described the limited aspects of the participants' activities in non-profit community-based intervention programs.

The purpose of this research is to obtain support guidelines so that volunteers in a non-profit com-munitybased invention program can more easily and effectively assist adults with aphasia. Two investigations were carried out to achieve this goal. One is a questionnaire survey given to program participants or their supporting families. The other is a morphological analysis of participants' speech at monthly meetings.

\section{Research Background}

\subsection{Community-Based Support Activity}

An aphasic patient usually visits the hospital at a certain interval after the initial discharge from the hospital. He or she typically lives in a community with his or her family. The International Classification of Functioning, Disability and Health (ICF) is a classification of health and health-related domains [4]. The ICF looks beyond the purely medical or biological conceptualization of dysfunction by taking into account other critical aspects of a disability. Consequently, the impact of the environment and other contextual factors on the functioning of an individual or a population can be considered, analyzed, and recorded. This means, in addition to medical treatment, the community-based support, which improves the environment and other contextual life factors, aids rehabilitation because the support can significantly influence an individual's participation. Measures of both language impairment and functional communication can be broadly, positively, and significantly influenced by therapy services that are delivered to persons with aphasia in community-based programs.

\subsection{Activity of Yokohama Aphasic Partner Group}

The researched organization, the Yokohama Aphasia Partner Group in Yokohama City, consists of members with aphasia, their families, speech therapist (ST), psychiatric social workers, and volunteers in Yokohama City [5]. The members with aphasia, after the onset, received hospital treatment for a period of time and were then discharged from the hospital. After being discharged, they lived in the community. The aphasia group has a meeting every month. Currently, 20 adults with aphasia are registered as members. Most members are in their $50 \mathrm{~s}$ or $60 \mathrm{~s}$, and usually 10 - 15 members attend each monthly meeting. Table 1 shows a typical program of a monthly meeting. The meetings are usually held from 1:00 PM to 4:00 PM on the second Sunday of the month. Program-1, "Warm-up physical exercise and vocal training”, and Program-3, "Language game for training”, are conducted by speech therapists (ST) with the support of volunteers. Much time is usually assigned to Program-3, "Individual oral presentation of a recent activity", with the support of other members with aphasia, speech therapists (ST), and volunteers.

The programs and other discussion results are recorded and edited as a Monthly Group Record. The record is

Table 1. Typical program of a monthly meeting.

\begin{tabular}{|c|l|}
\hline No. & Item \\
\hline 1 & Warm-up physical exercise and vocal training \\
\hline 2 & Individual oral presentation of a recent activity \\
\hline & Tea break \\
\hline 3 & Language game for training \\
\hline 4 & Singing Japanese songs with other members \\
\hline
\end{tabular}


printed and distributed to the members, language-and-hearing therapists (ST), and volunteers, as well as to related social welfare activity groups and organizations. The record is also up-loaded to the group web site so that aphasia can become better recognized by the public.

\section{Investigation Methods and Results}

\subsection{Questionnaire Method}

The investigation on the members with aphasia was carried out by the questionnaire method. Questionnaire sheets were sent to all members in February 2015 [6]. Ten of the 20 members sent back their filled-in sheets. Some of the respondents seemed to need the support of their families to complete the questionnaire. Figure 1 shows the results of the questionnaire. The results indicate that, in addition to the rehabilitation of aphasia and recovery of language functions such as vocal exercises and language games, the members attend the meeting because they can meet each other on a regular basis and can express or listen to recent activities.

\subsection{Morphological Analysis of Members' Speech at Monthly Meetings}

The "individual oral presentation of the recent activity" (Program-2 in Table 1) is analyzed as follows.

1. Analyzed months: 6 months from December 2013 to July 2014.

(The meeting in February 2014 was cancelled due to heavy snow)

2. Subjects: four males in their $50 \mathrm{~s}$ and $60 \mathrm{~s}$ (Subjects A, B, C, D)

3. Software: Excel, R, MeCab (Japanese language morphological analysis software)

Table 2 shows the frequent themes of utterances in the presentations. The following three themes were frequently mentioned: (1) action and status of a member, (2) interaction with friends, (3) emotion and cognition of a member's action.

Figure 2 shows the frequency of spontaneous/responsive utterances. A subject who is unwilling to talk could respond if another person asked a question.

The Japanese language morphological analysis software extracted uttered nouns from the recorded uttered data. The nouns are categorized as follows:

(1) Pronoun

(2) Numeral and number noun and quantifier,

(3) Time-presenting noun,

(4) Pronoun,

(5) Common noun.

Pronouns and common nouns are further classified by their meaning. Figure 3 shows the frequency of uttered noun categories. Table 3 shows the frequently uttered noun categories. These data show the following nouns were frequently uttered.

\section{Conclusions}

Two investigations, a questionnaire given to the program participants or their supporting families and a

Table 2. Frequent themes of utterances.

\begin{tabular}{|c|l|l|l|}
\hline $\begin{array}{c}\text { Qrder } \\
\text { Subject }\end{array}$ & \multicolumn{1}{|c|}{1} & \multicolumn{1}{c|}{2} & \multicolumn{1}{c|}{3} \\
\hline A & Action and Status & Question, and Request & Emotion and Cognition \\
\hline B & Emotion and Cognition & Action and Status & Interaction with Friends \\
\hline C & Action and Status & Interaction with friends & Emotion and Cognition \\
\hline D & Emotion and Cognition & Action and Status & Interaction with Friends \\
\hline
\end{tabular}

Table 3. Frequently uttered noun categories.

\begin{tabular}{|c|l|l|l|l|}
\hline $\begin{array}{c}\text { Okder } \\
\text { Subject }\end{array}$ & \multicolumn{1}{|c|}{ 1st. } & \multicolumn{1}{|c|}{ 2nd. } & \multicolumn{1}{|c|}{ 3rd. } \\
\hline A & Numeral,Number Noun,Quantifier & Proper Noun/Place & Common Noun/Place & Common Noun/Action \\
\hline B & Numeral,Number Noun,Quantifier & Time-presenting Noun & Common Noun/Action & Proper Noun/Place \\
\hline C & Numeral,Number Noun,Quantifier & Time-presenting Noun & Common Noun/Action & Proper Noun/Place \\
\hline D & Numeral,Number Noun,Quantifier & Common Noun/Person & Time-presenting Noun & Pronoun \\
\hline
\end{tabular}




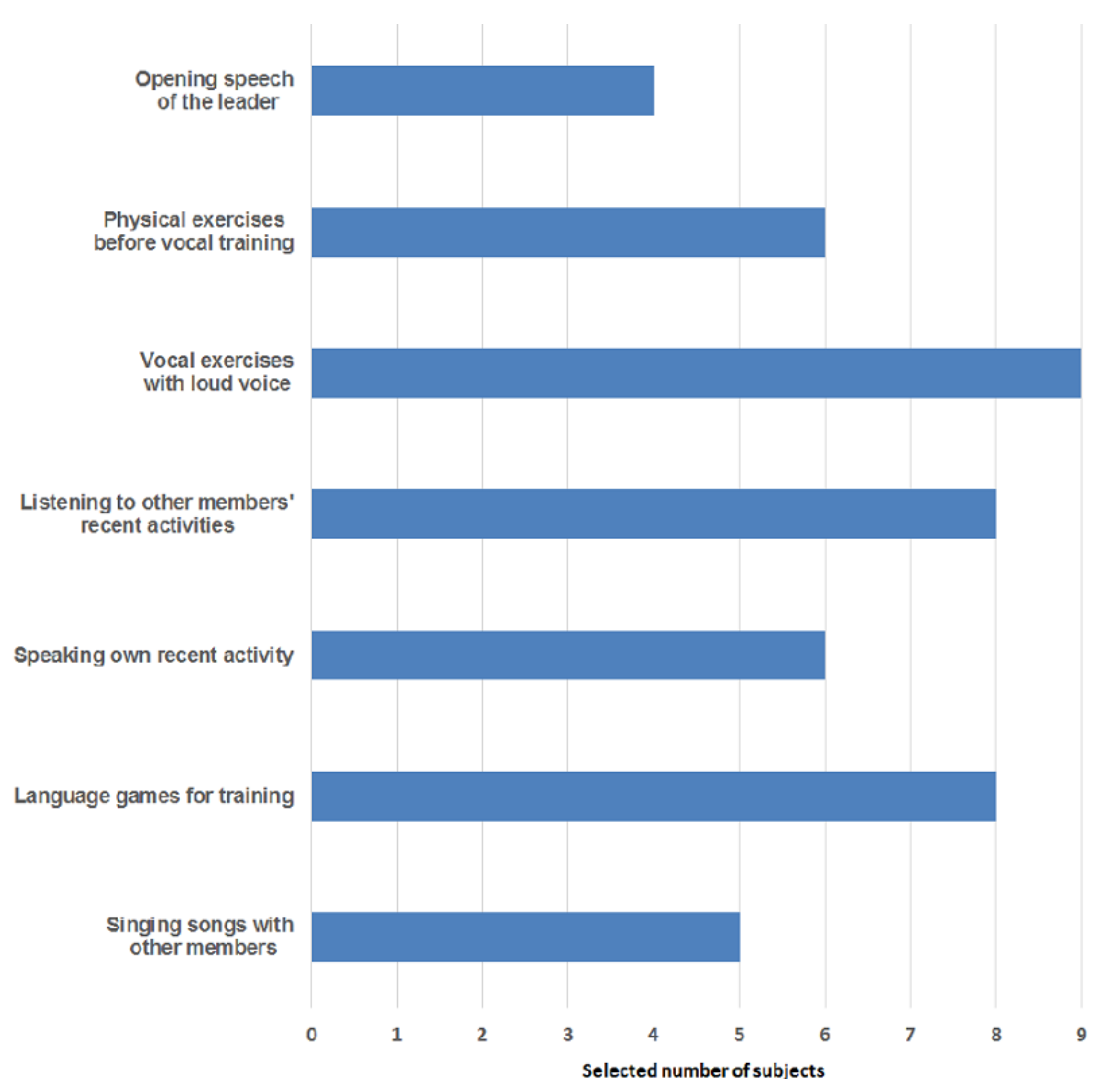

(a)

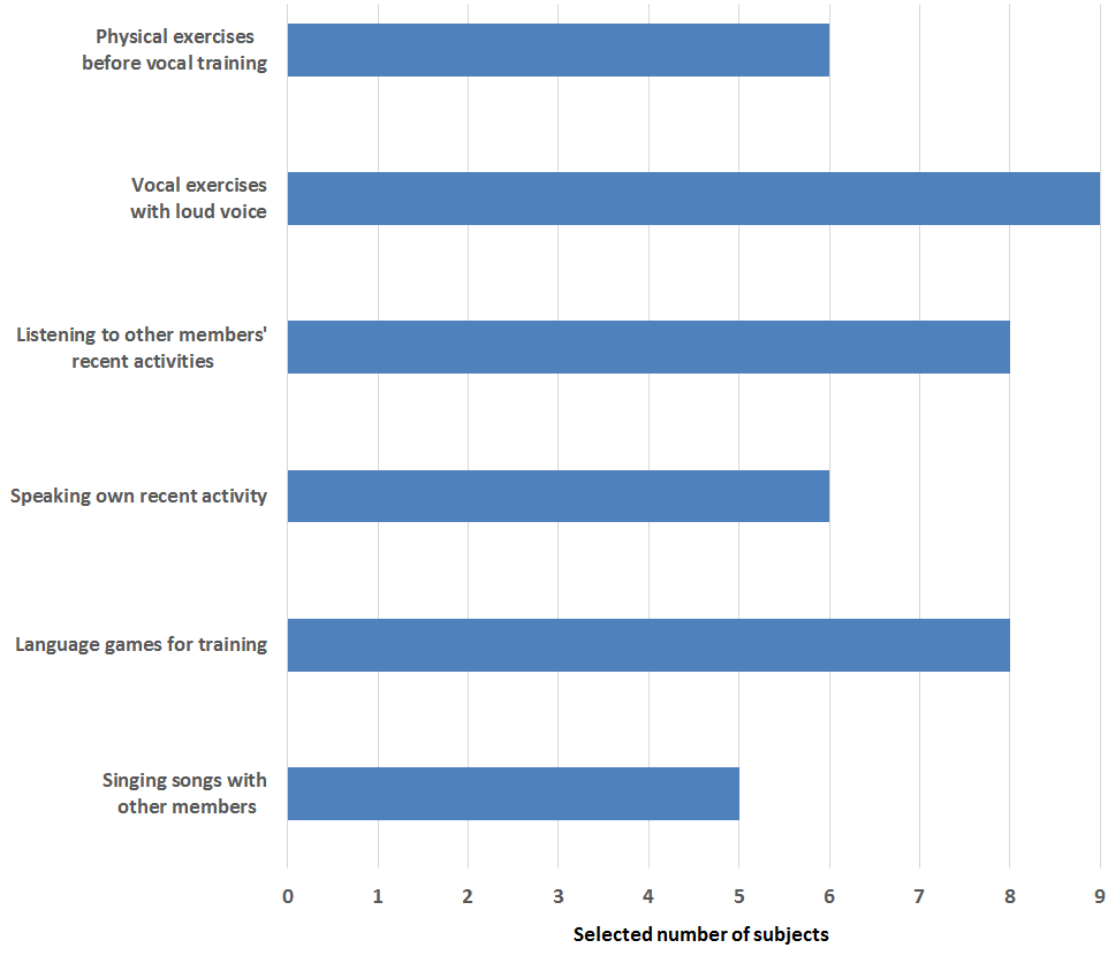

(b)

Figure 1. Results of questionnaire. The subjects were allowed to select plural items. (a) Motivational factors to attend a meeting; (b) Effective programs of a monthly meeting. 


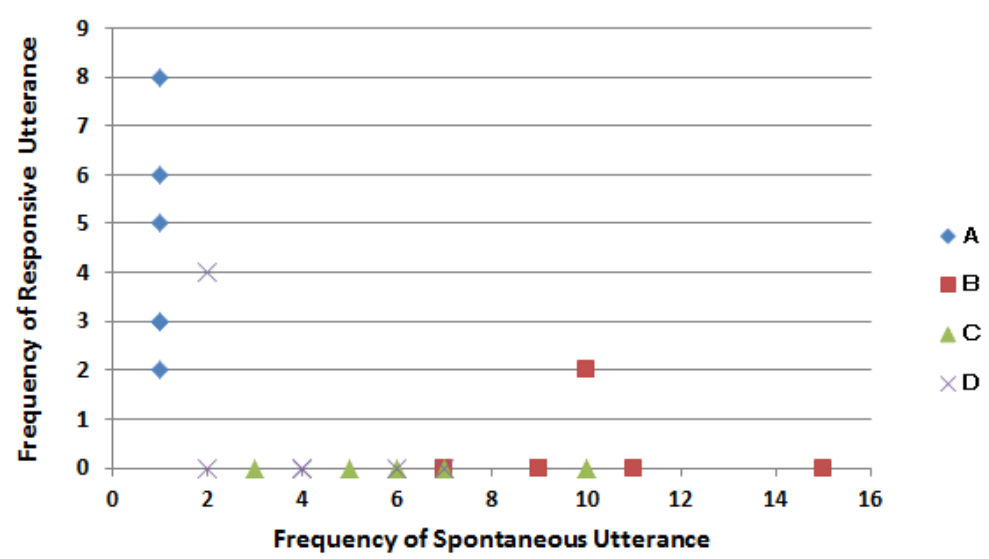

Figure 2. Frequency of spontaneous/responsive utterances.

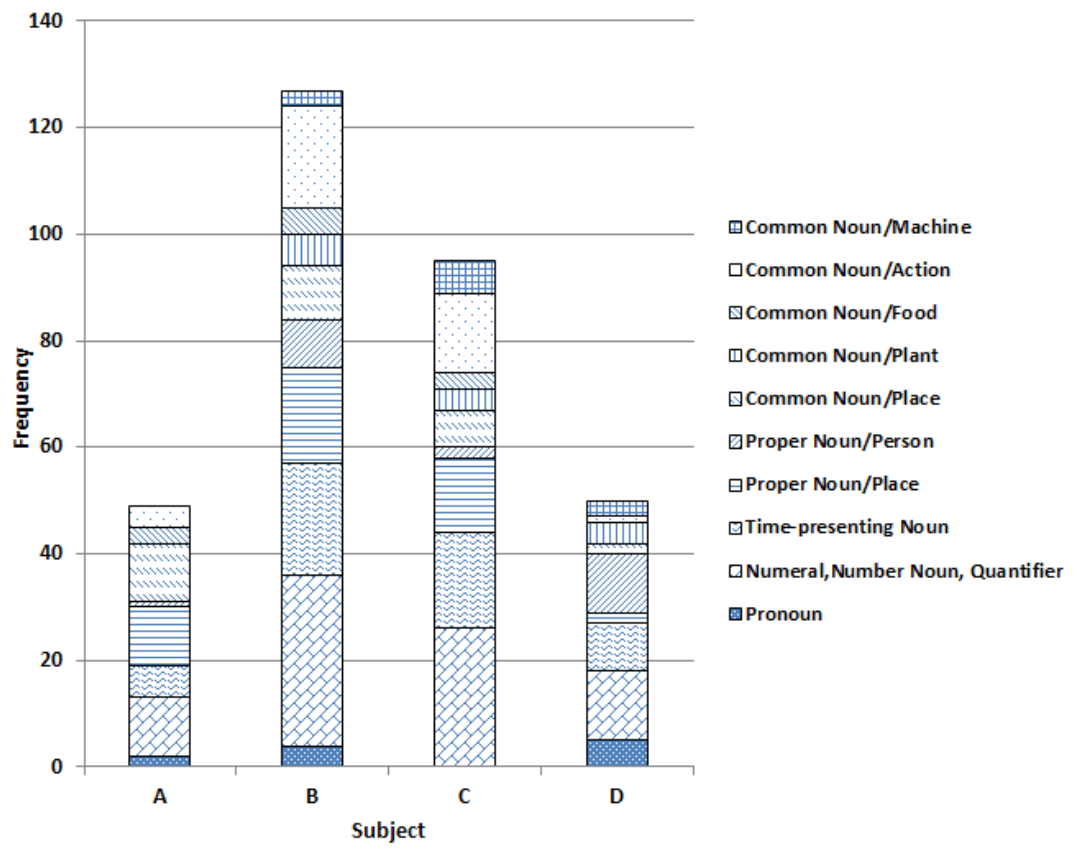

Figure 3. Frequency of uttered noun categories.

morphological analysis of the participants' speech at monthly meetings, were carried out to establish support guidelines so that volunteers in a non-profit community-based invention program can more easily and effectively assist adults with aphasia. Language-and-hearing therapists (ST) and volunteers can benefit by noting the following regarding points so that intervention programs can be operated effectively.

(1) In addition to the rehabilitation of aphasia and recovery of language functions by vocal exercises and language games, program members with aphasia are also interested in a monthly meeting as an opportunity to meet each other on a regular basis to express or listen to the recent activities of the members.

(2) In the program of "Individual oral presentation of a recent activity", the following three themes are frequently mentioned: (a) action and status of the member, (b) interaction with friends, (c) emotion and cognition of the member's action.

(3) The following nouns are frequently uttered:

- Numeral, number noun, quantifier, such as number of goods and date

- Time-presenting noun, such as New Year holiday

- Proper noun/place, such as Yokohama and Kamakura

- Common noun/action, such as a walk or sports event. 


\section{References}

[1] National Aphasia Association, Definition. http://www.aphasia.org/aphasia-definitions/

[2] Howea, Linda E. Worralla and Louise M. H. Hicksona, (2008) Interviews with People with Aphasia: Environmental Factors that Influence Their Community Participation, Aphasiology, 22, 1092-1120. http://dx.doi.org/10.1080/02687030701640941

[3] Aftonomos, L.B., Appelbaum, J.S. and Steele, R.D. (1999) Improving Outcomes for Persons with Aphasia in Advanced Community-Based Treatment Programs. Stroke, 30, 1370-1379. http://dx.doi.org/10.1161/01.STR.30.7.1370

[4] World Health Organization, International Classification of Functioning, Disability and Health (ICF). http://www.who.int/classifications/icf/icf_more/en/

[5] Yokohama Shitsugosho Tomono-kai (Yokohama Aphasia Partner Group in Yokohama City). (In Japanese) http://www.kounan-portal.com/3935/report.html

[6] 30th Anniversary Record of Yokohama Aphasia Partner Group (2015). (In Japanese) 